\title{
Epidemiological Characteristics of Great Depression Diseases of Hospitalized Patients in Psychiatric Hospital"Skopje" - Skopje for a Five Year Period From 2013 - 2017
}

\author{
Biljana Iliev, Irina Pavlovska, Andromahi Naumovska
}

\begin{abstract}
Severe depression beside the pathological mood, also denotes the cognitive, perceptual, and motor activities that are psychopathologically related to the scope of all psychic dynamics, which means cognitive, conative, and emotional. This mental illness covers a large area of the affective life of a man with a wide range of severe depression classified by ICD - 10 - F 32, F32.2 and F 32.3. By using a retrospective approach in the research will be gathered data from medical histories on biological and social factors that act positively or negatively on the occurrence and course of major depression. The research aims to determine the total number of patients with severe depression treated in hospital conditions in the Psychiatric Hospital „Skopje” - Skopje for a period of 5 years from 2013-2017 in order to get a clear picture of the factors and specific predictors that lead to development of major depression. Within the research methods all the parameters contained will be calculated so that it can be concluded that the predictors influence and differ from other stakeholders responsible for etiopathogenesis, although they have a mutual influence. From the obtained data we expect to obtain the scope of the influence of socio-demographic data on the occurrence of Major Depression and sequelae of the disease.
\end{abstract}

Keywords: severe depression, cognitive function, affectivity, mental illness, medical history

DOI: $10.7176 / \mathrm{JHMN} / 95-06$

Publication date: November $30^{\text {th }} 2021$

\section{Introduction}

Depressive illnesses affect a wide range of mental health changes, from sadness and fear, insomnia with psychosomatic disorders, to psychotic mental disorders such as severe depression, a chronic diagnostic entity $(1,2)$. The World Health Organization estimates that in all parts of the world, the majority of the population suffers from mental illness that manifests itself in depressive phenomena at least once in a lifetime regardless of gender, age, demographic and sociocultural characteristics, religious beliefs and demographic and sociocultural characteristics (3)

Terminologically and nosologically, depression is an affective disorder with a primary impairment (reduction) of cognitive functions, alteration of affectivity, psychomotor retardation, and social isolation. Thought content is depressing with suicide attempts or commits (4).

Research on hospitalized patients diagnosed with severe depression suggests that depressive disorders are among the top two leading causes of disability due to illness. The consequences of this disease and the loss of health are great. Depression is ranked by the WHO as the largest contributor to global disability $-7.5 \%$ of all ages in 2015. Globally, it is estimated that over 300 million people suffer from depression, which is equivalent to 4.4 percent of the world's population. The percentage of the global population with severe depression in 2015 is estimated at $4.4 \%$. Severe depression is more common in women $(5.1 \%)$ than men $(3.6 \%)$. Prevalence rates vary by age - peak in older adulthood (over 7.5\%) in women aged 55-74 years and over 5.5\% in men. The WHO does not have any data on the prevalence of severe depression in the Republic of North Macedonia for the period from 2005 to 2016 (which is the motive for starting this research) while in neighboring countries the data are: Albania $4.8 \%$, Bulgaria 5.2\%, Greece 5.7\% (5).

In recent years, the results of studies show that socio-demographic factors play a significant role in abnormal functional activity and are recognized as major causes for the pathogenesis and severity of severe depression. In Bangladesh, a study based on hospitalized patients investigating socio-demographic factors and their correlation with the severity of major depression (6) shows that 56\% (133) are men and $44 \%$ (106) are women. About 46\% (111) patients have secondary education. 56\% of married people tended to develop depression compared to $36 \%$ of unmarried people. Urban dwellers are $64 \%$ more likely to suffer from depression than those in rural areas. The correlation analysis shows that age, gender, marital status, education, family income and place of residence are related to the severity of the disease. In addition, among all - age, marital status and place of residence were positively correlated with the severity of major depression, while gender, education and family income were negatively correlated with the severity of depression. The socio-demographic factors associated with depression have been found to be low socio-economic status, poor educational background and widowhood.

In Canada, the prevalence of major depression was found in $15.4 \%$ of single mothers compared with $6.8 \%$ in married mothers. $(9,10)$. 
The current study shows that age, gender, education, employment status - unemployment, marital status, place of residence are associated with the severity of depression and is a challenge for research in the field of affective disorders in psychiatry.

\section{Objectives}

The main goal is to determine the total number of patients with severe depression treated in the Psychiatric Hospital "Skopje" - Skopje in a period of 5 years, retrospectively in the period of 2013 until 2017 and to determine the impact of socio-demographic variables as risk factors and predictors.

\section{Ancillary goals}

1. To get a clear picture of the percentage of Severe Depression in the period from 2013-2017

2. Gender, age, education, employment, marital status, place of residence (rural or urban environment) as sociodemographic characteristics affect the occurrence of Severe depression

\section{Material and methods}

Population, sample and instruments

The study is retrospective and was performed by collecting data from the medical documentation of treated patients in the Psychiatric Hospital "Skopje" - Skopje, in the period from 2013. until 2017 From the total number of patients treated in the hospital (5538) over 18 years of age, a sample is made up of patients diagnosed with ICD 10 with a diagnosis of - F32, Severe depression, F32.2 - Severe depressive episode without psychiatric symptoms and F 32.3 Severe depression episode with psychotic symptoms.

Since the aim of the research was to get a clear picture of which of the socio-demographic characteristics have the greatest impact on the occurrence of Major Depression, a short questionnaire was created containing items on the sex, age, education and marital status of the patients in the sample and it was completed by downloading data from patients medical records.

The conducted research was quantitative using descriptive statistics, frequencies, percentages and other statistical methods, summarized and presented in a clear way in tables and graphs in order to summarize the data in a clear way

The collected data were statistically processed in SPSS program. The percentage of Severe Depression in the Psychiatric Hospital "Skopje" - Skopje was determined and its characteristics are shown in the sample with descriptive statistics. Cross-tabulation has examined the influence of various factors on the occurrence of Severe Depression.

Inclusion criteria

- Patients with severe depression with and without psychotic elements

Exclusion criteria

- Bipolar affective disorder

- Depressive stages in patients with schizophrenia

- Senile paranoid - depressive disorders

\section{Results}

The total number of admissions in the Psychiatric Hospital "Skopje"- Skopje in the period from 2013 to 2017 has decreased in the last three years. In contrast, the number of patients with severe depression being treated in hospital is increasing, especially in 2013 and 2014. 


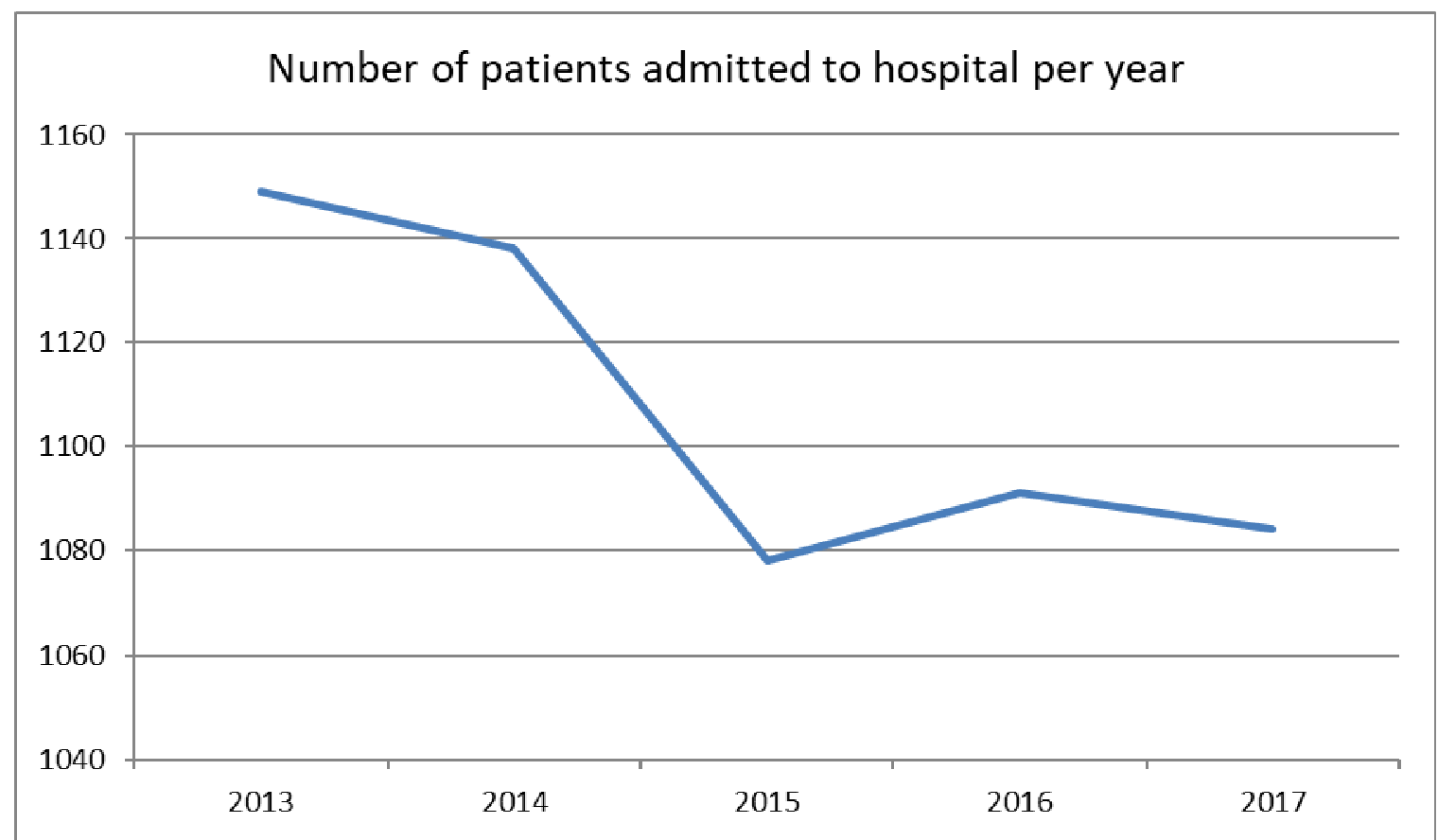

Figure 1. Number of patients admitted to hospital in the period 2013-2017

Out of a total of 5,538 hospitalized patients, 28 were diagnosed with Severe Depression. In 2013 out of a total of 1149 patients admitted, $5(0.4 \%)$ are with severe depression. In 2014, out of a total of 1138 patients, 6 $(0.52 \%)$ are with severe depression. In 2015 out of 1078 patients admitted, $5(0.46 \%)$ are with Severe depression. In 2016 out of 1091 hospitalized patients, $14(1.28 \%)$ are with Severe Depression. In 2017 out of a total of 1084 patients, $6(0.55 \%)$ are with Severe Depression (Figure 2).

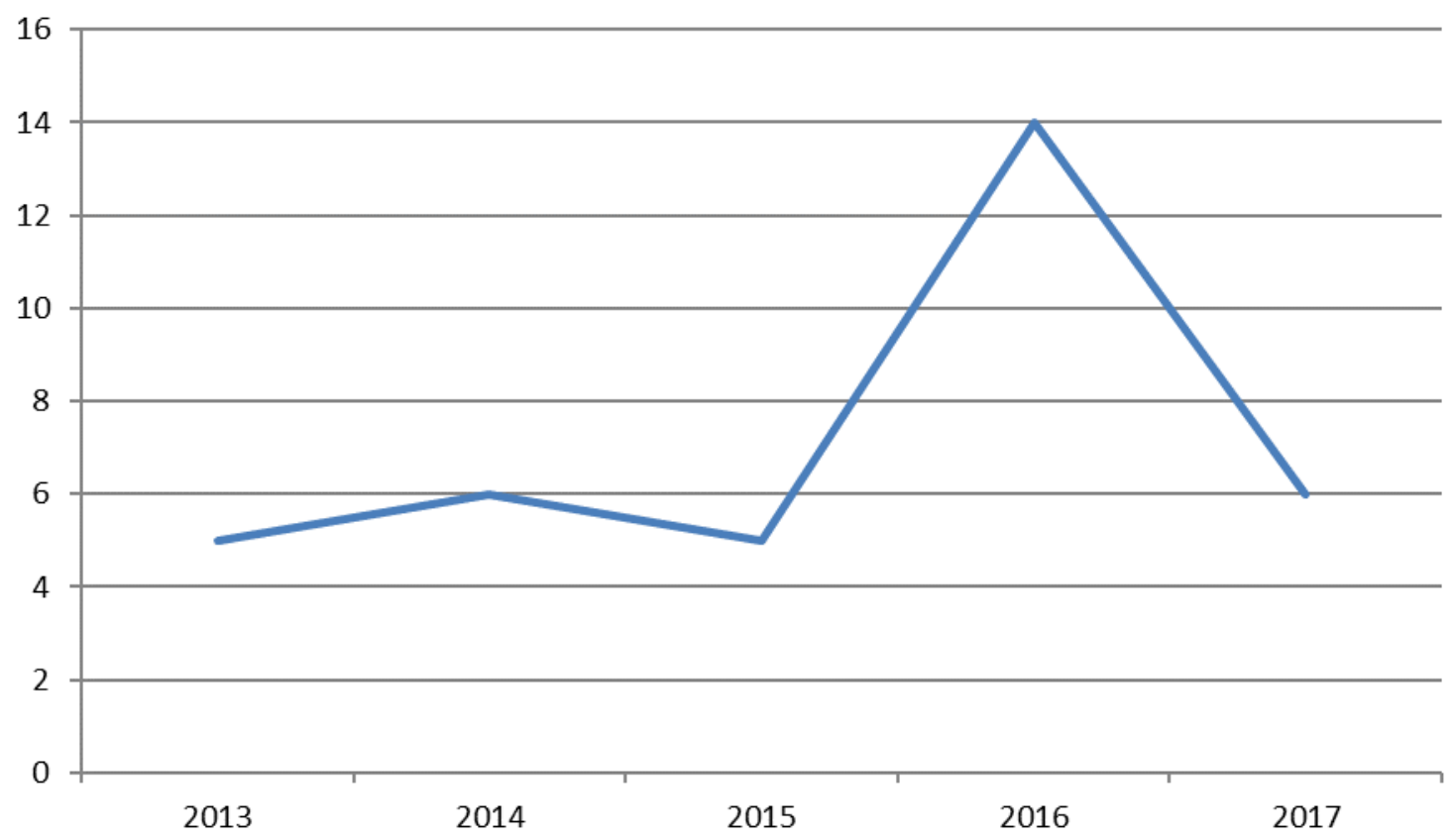

Figure 2. Number of patients with severe depression admitted to hospital in the period 2013-2017

The sample is composed of a total of 28 patients with severe depression who were hospitalized in the Psychiatric Hospital "Skopje" in the period 2013-2017. 42.9\% of them are men and 57.1\% women, which shows a higher prevalence of women with major depression in this hospital, compared to men (Figure 3). 


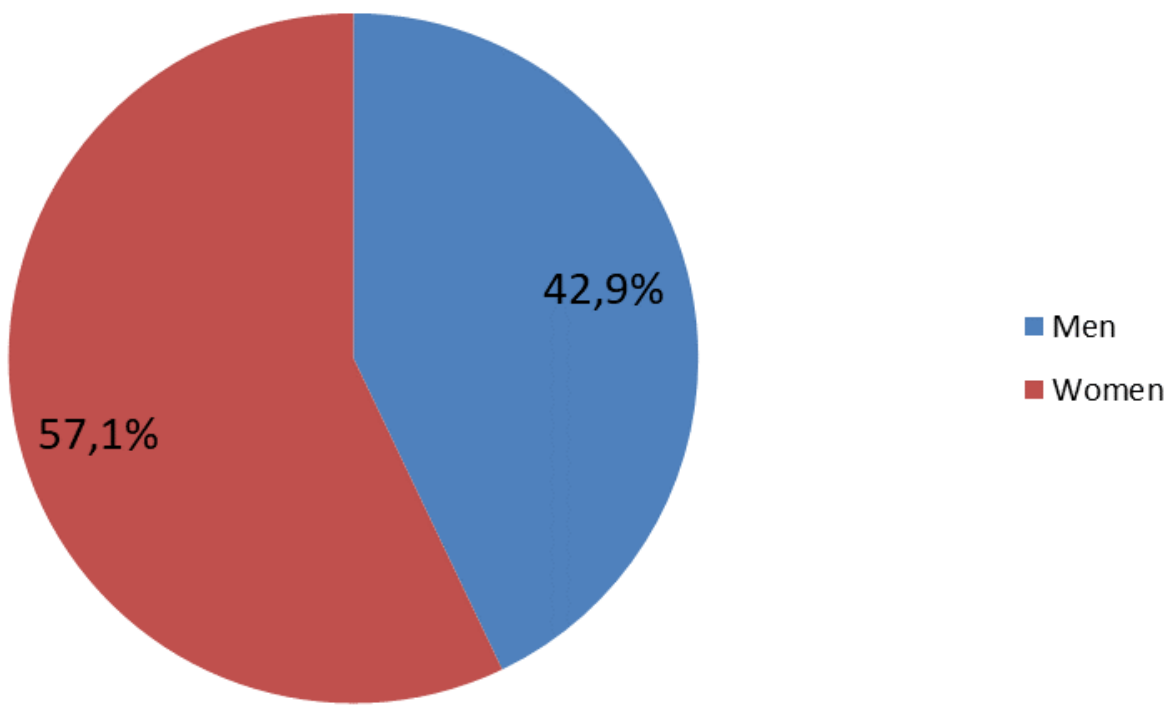

Figure 3. Distribution of patients with severe depression according to variable sex

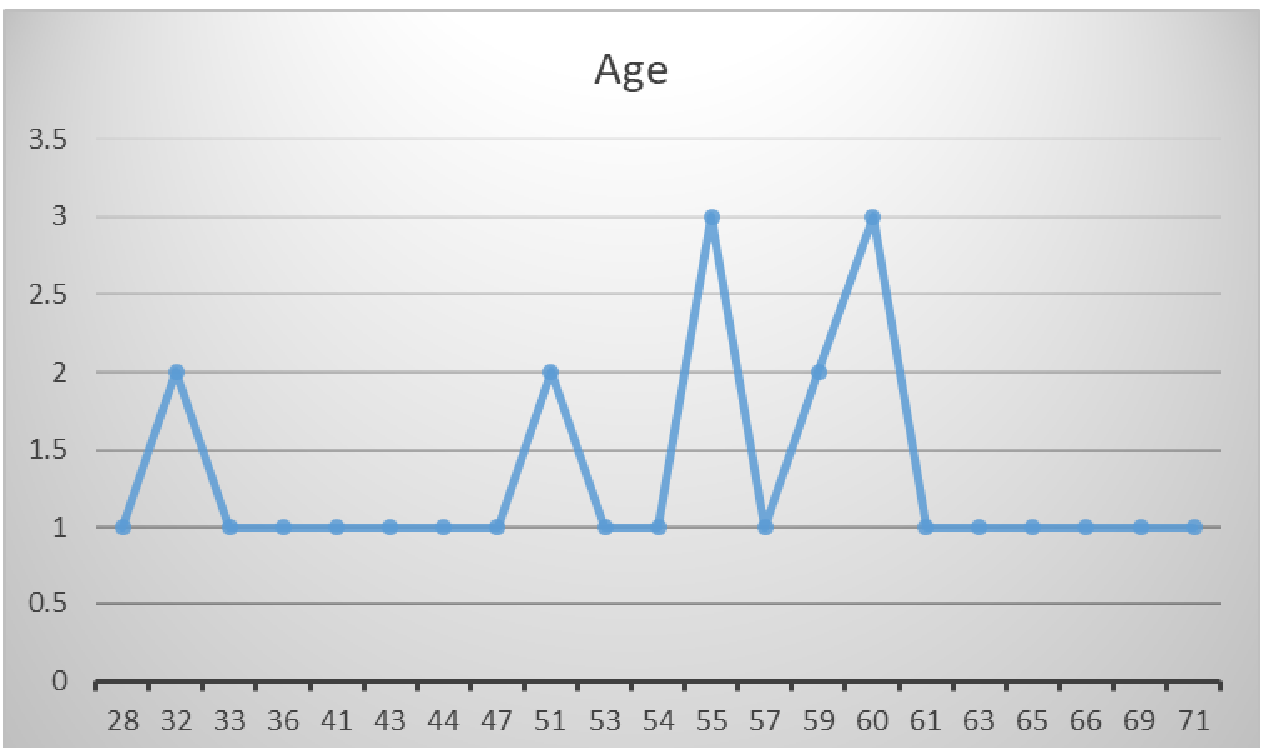

Figure 4. Number of patients with severe depression according to variable age

In terms of age in patients with severe depression, a range of 28 to 71 years of age is observed, but with an increased frequency between 55 and 60 years. The average age of the respondents is 52.14 years.

Most $(68 \%)$ of the patients have completed secondary education, and the least are with higher education, ie only two $(7.1 \%)$ (Figure 5). 


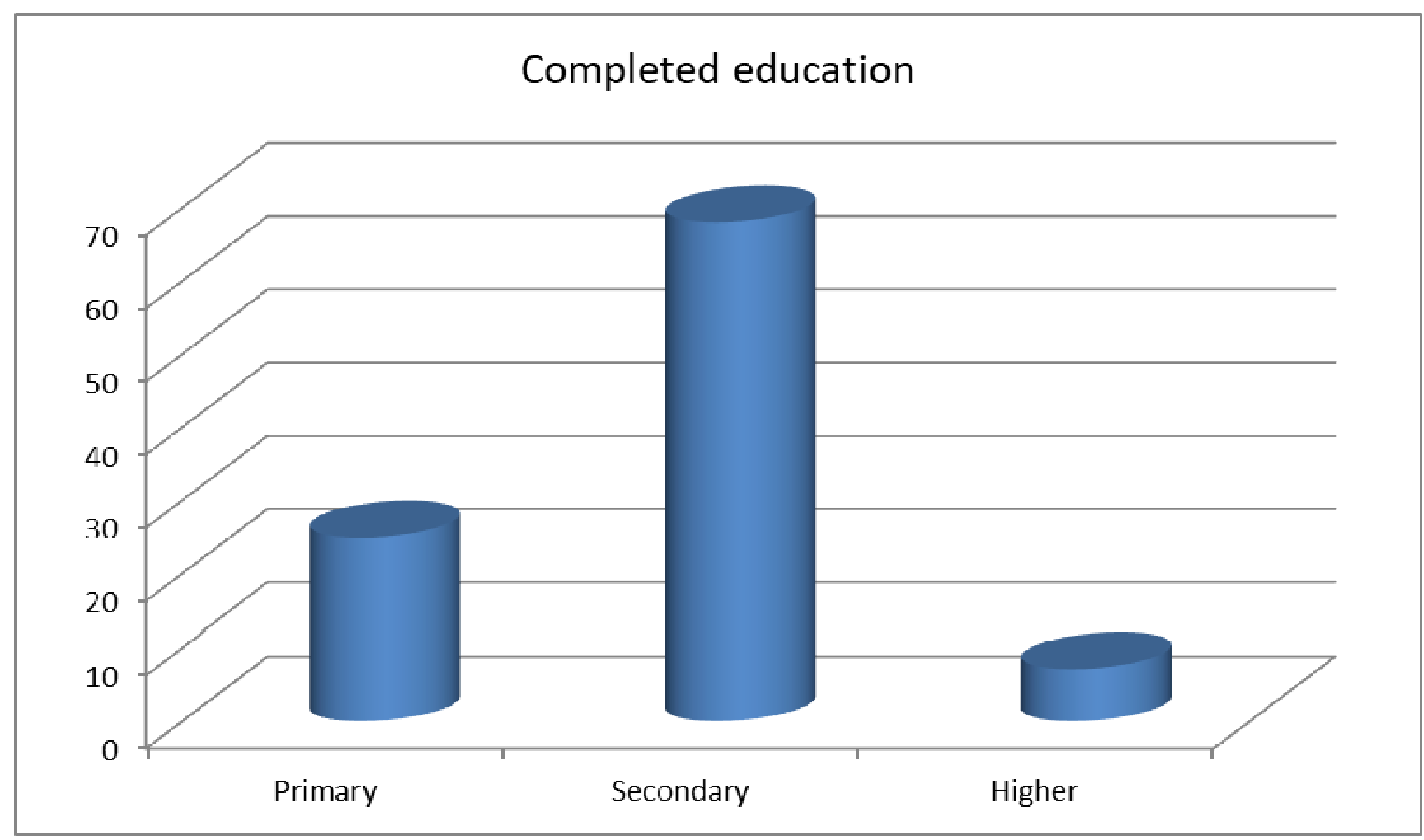

Figure 5. Distribution of patients with severe depression according to variable education

Most of those who have completed only primary education (71.4\%) are women, but ANOVA did not find a statistically significant difference between the sexes in terms of completed level of education (Sig.0,436).

\begin{tabular}{|c|c|c|c|c|c|c|}
\hline & & & \multicolumn{3}{|c|}{ Education } & \multirow{2}{*}{-Total } \\
\hline & & & Primary & Secondary & Higher & \\
\hline \multirow[t]{8}{*}{ Sex } & & Count & 2 & 9 & 1 & 12 \\
\hline & \multirow{3}{*}{ Men } & $\%$ within sex & $16,7 \%$ & $75,0 \%$ & $8,3 \%$ & $100,0 \%$ \\
\hline & & $\%$ within education & $28,6 \%$ & $47,4 \%$ & $50,0 \%$ & $42,9 \%$ \\
\hline & & $\%$ of Total & $7,1 \%$ & $32,1 \%$ & $3,6 \%$ & $42,9 \%$ \\
\hline & \multirow{4}{*}{ Women } & Count & 5 & 10 & 1 & 16 \\
\hline & & $\%$ within sex & $31,3 \%$ & $62,5 \%$ & $6,3 \%$ & $100,0 \%$ \\
\hline & & $\%$ within education & $71,4 \%$ & $52,6 \%$ & $50,0 \%$ & $57,1 \%$ \\
\hline & & $\%$ of Total & $17,9 \%$ & $35,7 \%$ & $3,6 \%$ & $57,1 \%$ \\
\hline \multirow{4}{*}{ Total } & & Count & 7 & 19 & 2 & 28 \\
\hline & & $\%$ within sex & $25,0 \%$ & $67,9 \%$ & $7,1 \%$ & $100,0 \%$ \\
\hline & & $\%$ within education & $100,0 \%$ & $100,0 \%$ & $100,0 \%$ & $100,0 \%$ \\
\hline & & $\%$ of Total & $25,0 \%$ & $67,9 \%$ & $7,1 \%$ & $100,0 \%$ \\
\hline
\end{tabular}

Table 1. Distribution of patients according to variables sex and education

Regarding the activity of the patients, it is noticed that only 8 of them, ie $28.6 \%$ are employed, and even $71.4 \%$ are unemployed (Figure 6). 


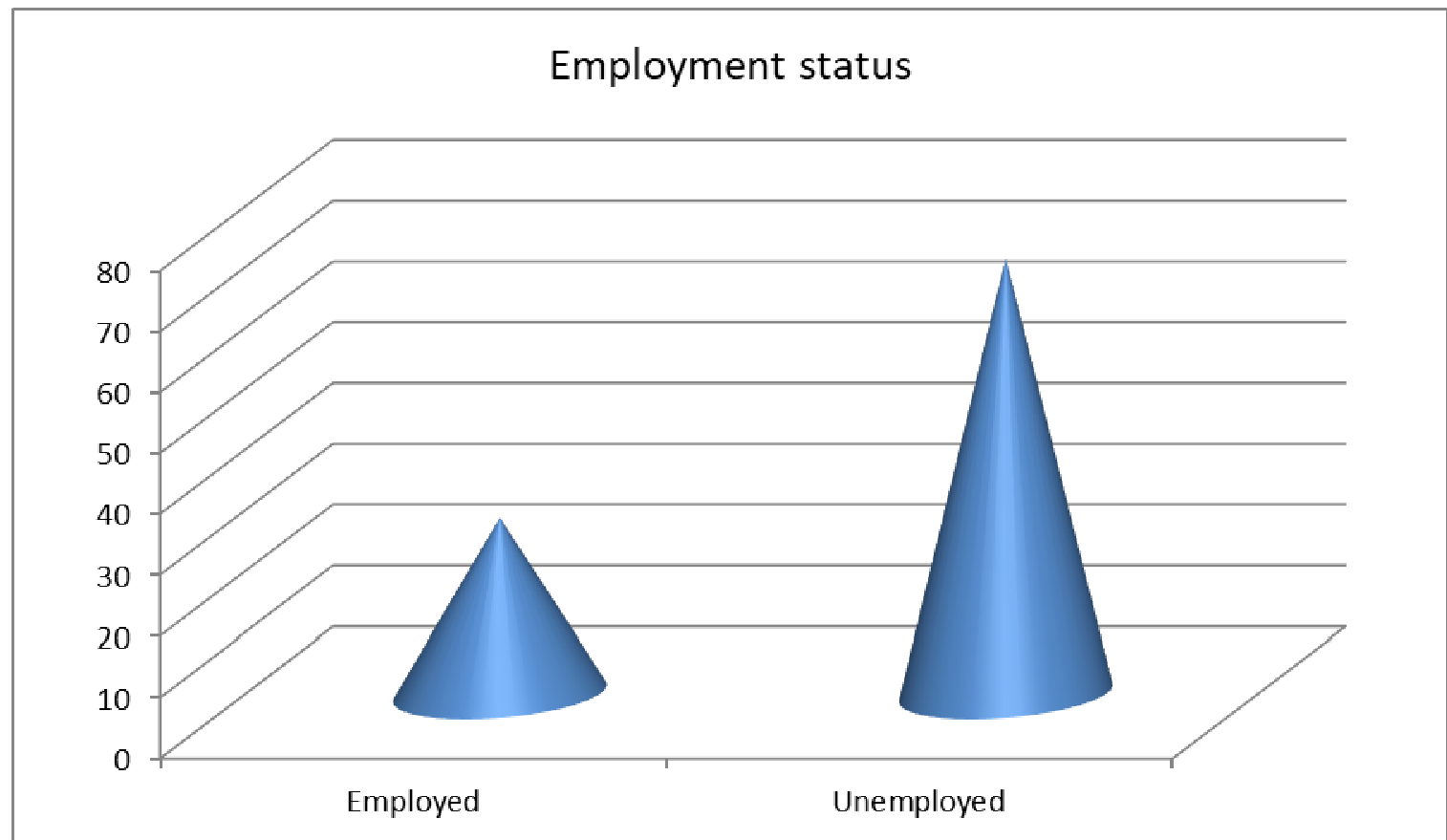

Figure 6. Distribution of patients with severe depression according to employment status

Most of the patients (53.6\%) are married, $21.4 \%$ are widowed, $17.9 \%$ are single and only $7.1 \%$ are divorced. No statistical significant difference were found between patients with specific marital status in terms of gender, employment / unemployment and place of residence (Figure 7).

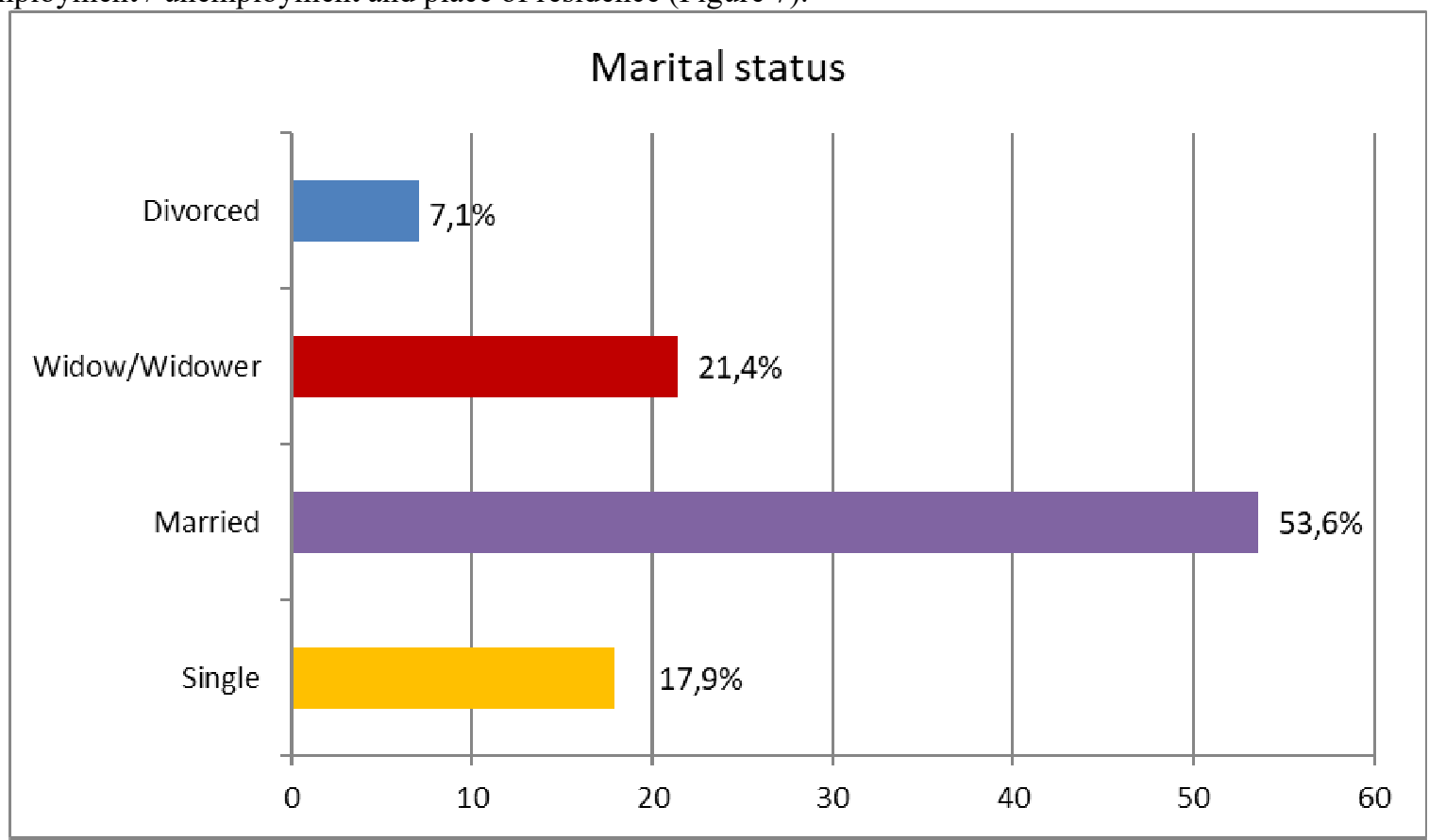

Figure 7. Distribution of patients with severe depression according to marital status

From the display of the intersection of the variables employment and marital status in Table 2, can be noticed that all those who are divorced are unemployed, but $73.3 \%$ of those who are married are also unemployed. Only patients who were single have completed higher education in this sample. 


\begin{tabular}{|c|c|c|c|c|c|}
\hline & & & \multicolumn{2}{|c|}{ Employment status } & \multirow[b]{2}{*}{ Total } \\
\hline & & & Employed & Unemployed & \\
\hline \multirow[t]{16}{*}{ Marital status } & Single & Count & 3 & 2 & 5 \\
\hline & & $\%$ within marital status & $60,0 \%$ & $40,0 \%$ & $100,0 \%$ \\
\hline & & $\%$ within employment status & $37,5 \%$ & $10,0 \%$ & $17,9 \%$ \\
\hline & & $\%$ of Total & $10,7 \%$ & $7,1 \%$ & $17,9 \%$ \\
\hline & Married & Count & 4 & 11 & 15 \\
\hline & & $\%$ within marital status & $26,7 \%$ & $73,3 \%$ & $100,0 \%$ \\
\hline & & $\%$ within employment status & $50,0 \%$ & $55,0 \%$ & $53,6 \%$ \\
\hline & & $\%$ of Total & $14,3 \%$ & $39,3 \%$ & $53,6 \%$ \\
\hline & Widow / & Count & 1 & 1 & 2 \\
\hline & Widower & $\%$ within marital status & $50,0 \%$ & $50,0 \%$ & $100,0 \%$ \\
\hline & & $\%$ within employment status & $12,5 \%$ & $5,0 \%$ & $7,1 \%$ \\
\hline & & $\%$ of Total & $3,6 \%$ & $3,6 \%$ & $7,1 \%$ \\
\hline & Divorced & Count & 0 & 6 & 6 \\
\hline & & $\%$ within marital status & $0 \%$ & $100,0 \%$ & $100,0 \%$ \\
\hline & & $\%$ within employment status & $0 \%$ & $30,0 \%$ & $21,4 \%$ \\
\hline & & $\%$ of Total & $0 \%$ & $21,4 \%$ & $21,4 \%$ \\
\hline \multirow[t]{4}{*}{ Total } & & Count & 8 & 20 & 28 \\
\hline & & $\%$ within marital status & $28,6 \%$ & $71,4 \%$ & $100,0 \%$ \\
\hline & & $\%$ within employment status & $100,0 \%$ & $100,0 \%$ & $100,0 \%$ \\
\hline & & $\%$ of Total & $28,6 \%$ & $71,4 \%$ & $100,0 \%$ \\
\hline
\end{tabular}

Table 2. Distribution of patients according to employment status and marital status

There is a big difference according to the place of residence, ie $85.7 \%$ live in urban areas, and only 4 people, ie $14.3 \%$ live in rural areas (Figure 8 ).

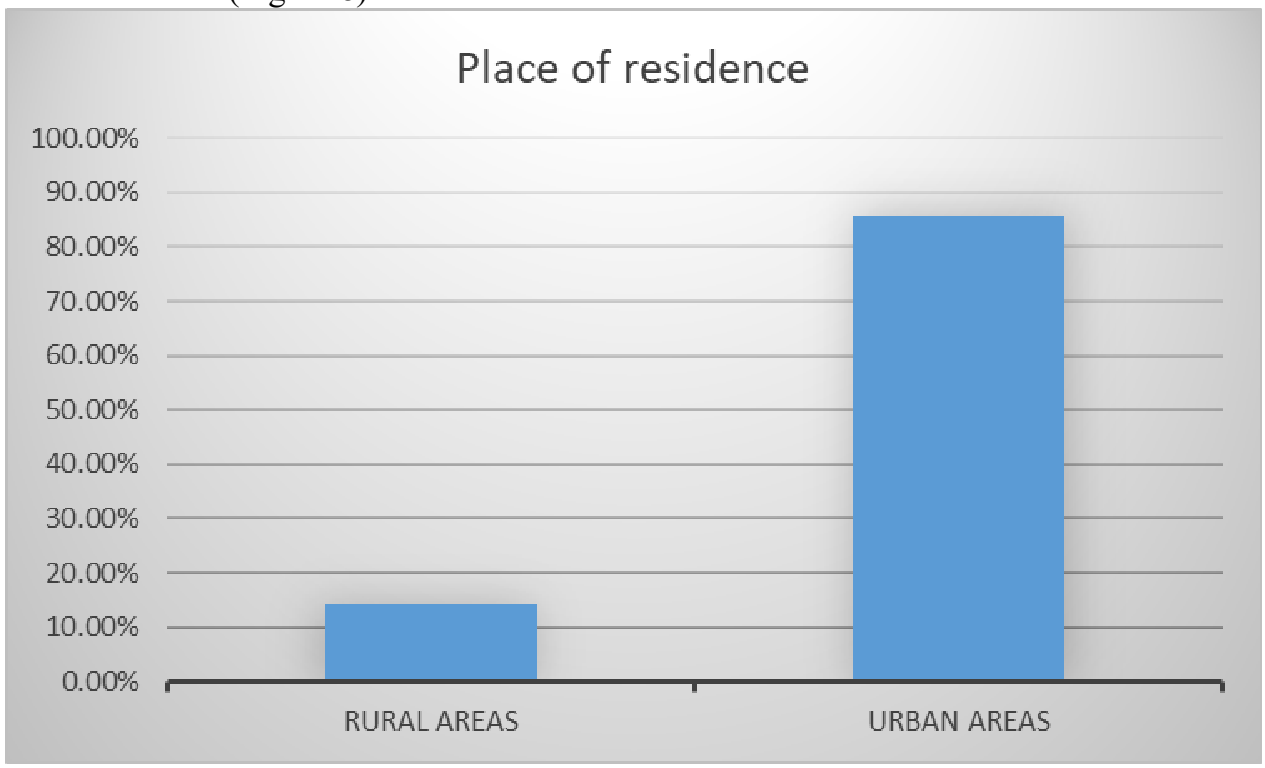

Figure 8. Distribution of patients with severe depression according to place of residence

\section{Discussion}

This study was conducted to investigate the socio-demographic status of patients with severe depression who were hospitalized in the Psychiatric Hospital "Skopje" - Skopje in the period 2013-2017. The correlation between socio-demographic status and the severity of the disorder was also found. Our study findings are comparable to similar previous studies in some other countries Germany, China, Canada.

In this study we found $42.9 \%$ of men and $57.1 \%$ of women, this gender ratio is in correlation with the findings of numerous global epidemiological studies that indicate twice the incidence of depression in women (Kessler 1993, Pedersen 2014). Subdiagnosis of depression is a global problem, and its roots are in its lack of knowledge, non-standard forms of manifestation (with predominant somatic symptomatology) and especially the 
stigma that depression carries with it (Zung 1993, Simon 1999, Kirmayer 1993).

According to the current study, patients with severe depression with an increased frequency between 55 and 60 years have been found. The average age of the respondents is 52.14 years. The findings regarding the age of onset of depression are consistent with epidemiological studies worldwide that indicate the onset of depression between the ages of 25 and 30 (Weissman 1996).

On the other hand, the average age over 50 again indicates the late start of treatment of depression in our environment due to untimely seeking help (impact of stigma) and its untimely diagnosis, so treatment actually begins with the manifestation of acute forms of depression that occur at a more advanced age and requiring necessary hospitalization.

According to the level of education, $67.9 \%$ of those found were with secondary education, $7.1 \%$ with higher education and $25 \%$ with primary education. The results are comparable to previous studies reporting an association between people with educational status and depression, significantly more severe depression occurs in those with lower education (13).

The results of the education of hospitalized patients with depression indicate a statistically significant higher incidence of low education, as well as unemployment. The above indicates the low socio-economic status of our respondents. Regarding the relationship between social status and the occurrence of depression, although there are conflicting findings, more research confirms a higher incidence of depression in poorer people (Blazer 1994, Kendrick 2015).

Among all respondents, $71.4 \%$ are unemployed, $28.6 \%$ are employed, which is in line with a study in China which claims that the lower the socio-economic status, the higher the rate of Severe Depression (13). Out of the total number of respondents, the percentage of Severe Depression according to marital status is higher among those who are married $(53.6 \%), 21.4 \%$ are widows, $17.9 \%$ are single and only $7.1 \%$ are divorced. This result is consistent with other previous studies where married people have an increased risk of developing major depression (14). $85.7 \%$ of urban residents are more likely to suffer from depression than $14.3 \%$ of rural residents, who are also similar to other findings (15).

With this study we can conclude that age, gender, marital status, level of education, employment / unemployment status and place of residence are associated with the severity of depression. Age, marital status and place of residence with Severe Depression are positively correlated with the severity of the illness, while education and employment / unemployment status are negatively associated with the severity of depression. This strong link between depression and socio-demographic status will play an important role in understanding and treating the disease.

Of particular interest is the fact that the number of patients in the Psychiatric Hospital "Skopje" - Skopje with well-developed psychiatric care and treatment is small because the indications for admission are stricter, and the time spent in hospital is shorter because he has developed inpatient treatment, which hospitalization is reduced. So, if we want to give a more accurate conclusion for our current study, we need to conduct it on a large number of samples from different regional parts of R. Macedonia. Despite these limitations, we hope that our study will play an important role in understanding the association between socio-demographic status and the severity of depression.

\section{Reference}

1. Predrag Kalicanin, Prof. dr. Psihijatrija I I II, Biblioteka „, PSIHIJATRIJA “Bgd. 1997 god.

2. Садок и Садок, Сеопфатен учебник за психијатрија, Табернакул, Скопје, 2012

3. World Health Organization. The World Health Report 2001 : Mental Health: New Understanding, New Hope. 2001. World Health Organization.

4. Kecmanovic D. Psihijatrija, Medicinska knjiga, Svjetlost, Beograd-Zagreb-Sarajevo 1989

5. World Health Organization (Depression and Other Common Menta Disorders, Global Health Estimates WHO 2017) ( World Health Organization, regional office in Europe)

6. Islam, Md.R. and Adnan, R. (2017) Socio-Demographic Factors and Their Correlation with the Severity of Major Depressive Disorder: A Population Based Study. World Journal of Neuro-science, 7, 193-202.

7. Mills, T.N. and Henretta, J.C. (2001) Racial, Ethnic and Sociodemographic Differences in the Level of Psychosocial Difference among Older Americans. Research on Ageing, 23, 131-152.

8. Eaton, W.W., Muntaner, C., Bovasso, G. and Smith, C. (2001) Socioeconomic Status and Depressive Syndrome: The Role of Inter- and Intra-Generational Mobility,

9. Government Assistance, and Work Environment. Journal of Health and Social Behavior, 42, 277-294

10. Lennon, M.C., Blome, J. and English, K. (2002) Depression among Women on Wel- fare: A Review of the Literature. Journal of the American Medical Women's Associ-ation, 57, 27-31, 40

11. Lorant, V., Deliège, D., Eaton, W., Robert, A., Philippot, P. and Ansseau, M. (2003) Socioeconomic Inequalities in Depression: A Meta-Analysis. American Journal of Epidemiology, 157, 98-112.

12. Kuehner,C (2003) Gender Differences in Unipolar Depression: An Update of Epidemiological Findings and 
Possible Explanations. Acta Psychiatrica Scandinavica, 108, 163 - 17

13. Shi, J., Zhang, Y., Liu, F., Li, Y., Wang, J., Flint., et al. (2014) Associations of Educational Attainment, Occupation, Social Class and Major Depressive Disorder among Han Chinese Women. PLoS ONE, 9, e 86674

14. Scott, K.M., Wells, J.E., Angermeyer, M., Brugha, T.S., Bromet, E., et al. (2010) Gender and the Relationship between Marital Status and First Onset of Mood, Anxiety and Substance Use Disorders, Psihological Medicine, 40, 1495-1505

15. Rural-urban differences in the prevalence of major depression and associated impairment.Depts. of Psychiatry \& of Community Health Sciences, Faculty of Medicine, University of Calgary, Calgary, Canada. 